\title{
Use of ecological momentary assessment to detect variability in mood, sleep and stress in bipolar disorder
}

Han Li ${ }^{1}$, Dahlia Mukherjee ${ }^{2}$, Venkatesh Basappa Krishnamurthy² ${ }^{2}$ Caitlin Millett ${ }^{2}$, Kelly A. Ryan ${ }^{3}$, Lijun Zhang ${ }^{4}$, Erika F. H. Saunders ${ }^{2+}$ and Ming Wang ${ }^{1 *+}+(0)$

\begin{abstract}
Objective: Our aim was to study within-person variability in mood, cognition, energy, and impulsivity measured in an Ecological Momentary Assessment paradigm in bipolar disorder by using modern statistical techniques. Exploratory analyses tested the relationship between bipolar disorder symptoms and hours of sleep, and levels of pain, social and task-based stress. We report an analysis of data from a two-arm, parallel group study (bipolar disorder group $\mathrm{N}=10$ and healthy control group $\mathrm{N}=10$, with $70 \%$ completion rate of 14-day surveys). Surveys of bipolar disorder symptoms, social stressors and sleep hours were completed on a smartphone at unexpected times in an Ecological Momentary Assessment paradigm twice a day. Multi-level models adjusted for potential subject heterogeneity were adopted to test the difference between the bipolar disorder and health control groups.

Results: Within-person variability of mood, energy, speed of thoughts, impulsivity, pain and perception of skill of tasks was significantly higher in the bipolar disorder group compared to health controls. Elevated bipolar disorder symptom domains in the evening were associated with reduced sleep time that night. Stressors were associated with worsening of bipolar disorder symptoms. Detection of symptoms when an individual is experiencing difficulty allows personalized, focused interventions.
\end{abstract}

Keywords: Multilevel models, Subject heterogeneity, Ecological Momentary Assessment, Mood disorders, Mania, Affective disorders

\section{Introduction}

Bipolar disorders (BD) are episodic, recurrent brain disorders characterized by manic (BD type I) or hypomanic (BD type II) episodes and depressive episodes causing disturbances in mood, motivation, hedonic capacity, activity levels, sleep, energy and judgment that impair functioning [1]. In the United States, approximately $1-4 \%$ of the population is affected by BD [2]. Diagnosis of $\mathrm{BD}$, as with other psychiatric disorders, relies largely on self-report of symptoms [1,3], however, it is difficult for

\footnotetext{
*Correspondence: mwang@phs.psu.edu

${ }^{\dagger}$ Erika F. H. Saunders and Ming Wang-co-senior authorship

1 Department of Public Health Science, Penn State College of Medicine, Penn State Milton S. Hershey Medical Center, 90 Hope Drive, Hershey, PA 17033, USA

Full list of author information is available at the end of the article
}

individuals to recall mood symptoms, and recall may be influenced by current mood state [4].

Most people with BD suffer from subsyndromal symptoms between manic and depressive episodes [5]. The presence of subsyndromal symptoms has been shown to increase the likelihood of emergence of a mood episode [6-8], and variability in mood symptoms has been associated with deficits in emotional processing [9], and functional impairment $[10,11]$. The temporal relationship between variables thought to affect mood such as sleep disturbance and psychosocial stress are important in determining the associated risk factors. Such patientreported data on sleep and psychosocial stressors can help determine when to intervene to prevent the development of a mood episode [12-17]. However, in the literature, the relationship between sleep and mood 
is not clear. For instance, in several longitudinal studies, longer sleep onset latency, longer wakefulness after sleep onset and lower sleep efficiency have been associated with higher negative affect in BD [14]. However, an experimental design to alter evening mood prior to sleep showed that induction of happy mood prior to sleep onset created a shorter sleep onset latency in the HC group, but not in $\mathrm{BD}$ group, a phenomenon perhaps akin to what we see in the naturalistic setting [18].

Through technological advancements, daily self-reporting of mood and behavior is more easily recorded than in the past and provides valuable information on symptoms during daily life than traditional research methods [19]. Ecological Momentary Assessment (EMA) is a methodology allowing participants to report on phenomena close in time to when symptoms are experienced and to document several events or time periods, often in 1 day $[16,17,20,21]$. In previous studies on EMA, technologies such as smart phones and computers have been used effectively to gather data in patients with BD [22-27]. In our prior study, we tested the feasibility of using EMA ratings collected for 14 days by smartphones with $70 \%$ completion rate of daily EMA surveys in BD and $\mathrm{HC}$ participants [28]. In the present work, we perform a secondary analysis using data from this prior study to conduct multi-level models adjusted for potential subject heterogeneity, and extend our findings.

\section{Main text}

\section{Design, sample and measures}

The research was approved by the Institutional Review Board (IRB) at the Hershey Medical Center (PSU COM IRB \# 00251, Approval 3/28/2014). This study protocol was designed to test the compliance of individuals in a $\mathrm{BD}$ and an $\mathrm{HC}$ group on completion of twice-daily mood and stress, and once daily sleep measures on a Motorola Droid RazrM smartphone provided to the subjects for the study for 14 days. The feasibility outcomes of the study have been described previously [28]. The participants were screened over the phone, then seen in person for one visit. During that visit, the Mini-International Neuropsychiatric Interview (MINI), version 5.0 [29] was completed, demographic data collected and the participants were instructed on the use of the smartphone.

The twice-daily mood and stress survey measures included single item questions rating mood, energy, speed of thoughts, impulsivity, and physical pain on a visual analogue scale. Mood was described to the participants as being positive/negative valance of subjective experience. Note that the measurement of mood is of the subjective experience and not of a diagnosed mood episode. Two questions assessing the current and preferred social situation (alone/with others) were assessed along a Likert scale. Task-based stress was measured through three questions assessing perception of skill, effort and preference of tasks on a Likert scale. Once daily, in the morning, the participants entered the time to bed the previous night, time to sleep the previous night, number of awakenings, final time of waking, and time out of bed. More details about the enrollment criteria and data structure can be referred to Additional file 1 .

\section{Statistical analysis \\ Within-subject variability in BD symptoms}

We tested the primary hypothesis that within-subject variability in the core $\mathrm{BD}$ symptoms of mood valance, speed of thoughts, energy and impulsivity was greater in the $\mathrm{BD}$ group than in the $\mathrm{HC}$ group. First, we calculated the intraclass correlation coefficient (ICC) for each group to examine the relative magnitude of between-person versus within-person variation. Then, we tested the level-1 heterogeneity of variance with the null hypothesis of no individual differences in within-person variation [30, 31]. Lastly, multilevel models were further applied to analyze the variation in $\mathrm{BD}$ symptoms and stressors between the $\mathrm{BD}$ and $\mathrm{HC}$ groups [32].

\section{Evaluation of the associations between $B D$ symptoms and sleep time}

To analyze the associations between core BD symptoms and sleep time, we answered the following questions: (I) are the core BD symptoms affected by prior nights' sleep duration, and does the effect last more than 1 day? (II) Are core $\mathrm{BD}$ symptoms during the day affecting that night's total sleep time, and does this effect last more than one night? Two analyses using the morning and evening measures of the core BD symptoms were conducted with details shown in Additional file 1. Similar multilevel models described above were fitted with the variables of age, gender, employment status, time (days), group $(1=\mathrm{BD} ; 0=\mathrm{HC})$, sleep time/BD symptoms as well as the interactions between group and sleep time/BD symptom (if not significant, excluded for the final model) included as fixed effects.

\section{Evaluation of effects of pain and social stress on $B D$ symptoms}

To analyze the association between pain or social and task-based stressors (i.e., social stress, perception of skill) and core BD symptoms, we adopted similar models above with BD symptoms as longitudinal outcomes, and the pain or social stressors were included as time-varying covariates with fixed effects. The other variables including group $(1=\mathrm{BD} ; 0=\mathrm{HC})$, age, gender, employment status and time (days) as well as the interaction of group and the pain or social stressors (if not 
significant, were excluded for the final model) were also considered as fixed effects.

The strategies to handle small sample size are provided in Additional file 1. All hypotheses tests are two-sided with the significance level of 0.05 . Data was analyzed using SAS 9.4 Software with the MIXED Procedure.

\section{Results}

All BD participants were diagnosed with BD, type I. The groups did not differ significantly based on age, gender and employment status $(\mathrm{p}>0.05)$.
Within-subject variability in BD symptoms (Table 1)

Table 1 summarizes the analysis of distribution and difference in within-person and between-person variability between the $\mathrm{BD}$ group and $\mathrm{HC}$ group in $\mathrm{BD}$ core symptoms, stressors and pain (i.e., the ICC for mood in the $\mathrm{BD}$ group is 0.55 , indicating $55 \%$ between-person variation and $45 \%$ within-person variability). For multilevel models, no significant fixed effects for time were found. Overall, higher within-person variabilities in core BD symptoms as well as pain and perception of skill were shown in the $\mathrm{BD}$ group compared to the $\mathrm{HC}$ group (Table 1). There were no group differences in the mean scores of speed of thoughts, impulsivity, social stress,

Table 1 Variability of BD symptoms and stressors between BD and HC groups over the 14-day period

\begin{tabular}{|c|c|c|c|c|c|}
\hline & ICC & $\begin{array}{l}\text { Estimates of group effect } \\
\text { on within-person variability } \\
\left(a_{1}\right)\end{array}$ & $\begin{array}{l}\text { p-value for group } \\
\text { effect on within-person } \\
\text { variability }^{\mathrm{a}}\end{array}$ & $\begin{array}{l}\text { Estimates of between-group } \\
\text { difference the mean level } \\
\text { of symptoms or stressors }\left(\gamma_{01}\right)\end{array}$ & $\begin{array}{l}\text { p-value for between-group } \\
\text { difference in the mean level } \\
\text { of symptoms or stressors }\end{array}$ \\
\hline \multicolumn{6}{|l|}{ Mood } \\
\hline $\mathrm{BD}$ & 0.55 & 0.86 & $<0.0001$ & -18.42 & 0.015 \\
\hline $\mathrm{HC}$ & 0.72 & & & & \\
\hline \multicolumn{6}{|c|}{ Energy } \\
\hline $\mathrm{BD}$ & 0.49 & 1.02 & $<0.0001$ & -20.99 & 0.006 \\
\hline $\mathrm{HC}$ & 0.61 & & & & \\
\hline \multicolumn{6}{|c|}{ Speed of thoughts } \\
\hline $\mathrm{BD}$ & 0.40 & 1.73 & $<0.0001$ & -0.10 & 0.99 \\
\hline $\mathrm{HC}$ & 0.67 & & & & \\
\hline \multicolumn{6}{|c|}{ Impulsivity } \\
\hline $\mathrm{BD}$ & 0.16 & 0.89 & $<0.0001$ & 13.42 & 0.07 \\
\hline $\mathrm{HC}$ & 0.68 & & & & \\
\hline \multicolumn{6}{|l|}{ Pain } \\
\hline $\mathrm{BD}$ & 0.80 & 1.64 & $<0.0001$ & 38.75 & 0.001 \\
\hline $\mathrm{HC}$ & 0.40 & & & & \\
\hline \multicolumn{6}{|c|}{ Social stress } \\
\hline $\mathrm{BD}$ & 0.20 & 0.03 & 0.85 & 0.61 & 0.06 \\
\hline $\mathrm{HC}$ & 0.02 & & & & \\
\hline \multicolumn{6}{|c|}{ Perception of skill } \\
\hline $\mathrm{BD}$ & 0.23 & 0.65 & $<0.0001$ & 0.84 & 0.05 \\
\hline $\mathrm{HC}$ & 0.54 & & & & \\
\hline \multicolumn{6}{|l|}{ Effort } \\
\hline $\mathrm{BD}$ & 0.12 & 0.10 & 0.50 & 0.28 & 0.53 \\
\hline $\mathrm{HC}$ & 0.23 & & & & \\
\hline \multicolumn{6}{|c|}{ Preference of tasks } \\
\hline $\mathrm{BD}$ & 0.13 & 0.06 & 0.68 & 0.48 & 0.17 \\
\hline $\mathrm{HC}$ & 0.11 & & & & \\
\hline \multicolumn{6}{|c|}{ Sleep (h) } \\
\hline $\mathrm{BD}$ & 0.46 & 0.73 & $<0.0001$ & -0.67 & 0.27 \\
\hline $\mathrm{HC}$ & 0.30 & & & & \\
\hline
\end{tabular}

ICC intraclass correlation coefficient

a The $p$-values for group effect on within-person variability

b The $p$-values for between-group difference in the mean level of symptoms or stressors. Significant results are in italic 
perception of skill, effort or task preference. The significant results above remained same after correction for multiple testing, thus original p-values are presented.

\section{Evaluation of the associations between BD symptoms and sleep time (Table 2)}

The effect of the prior hours of sleep on BD symptoms in the morning of the index day across 13 days were examined with no significant results (Additional file 1: Table S1, p >0.05). Also, we tested the effect of evening symptoms on total hours of sleep for the same night (Model 1) and the same night plus the subsequent night (Model 2). Evening mood symptoms had a negative relationship to sleep, indicating elevated mood was associated with a decrease in sleep hours in the subsequent night $(p=0.03)$. The same effect was found for energy $(p=0.04)$. Elevated speed of speed of thoughts and impulsivity were associated with decreased sleep for the next night only $(\mathrm{p}<0.05)$.

\section{Evaluation of effects of pain and social stress on BD symptoms (Table 3 )}

We evaluated the effect of pain, social stress, perception of skill, effort and task-preference on mood symptoms at the same time point. Mood (Table 3A) was associated inversely with pain, and positively with task preference; mood was not associated with social stress, task effort or skill. Elevated energy (Table 3B) was associated with

Table 2 The associations between core BD evening symptoms during/before each day and that night's sleep time

\begin{tabular}{llll}
\hline Variable & \multicolumn{3}{l}{ Final selected model } \\
\cline { 2 - 4 } & Estimate & SE & p-value \\
\hline $\mathrm{BD}$ & -1.79 & 0.84 & 0.04 \\
$T_{\text {mood }}$ & -0.01 & 0.01 & 0.16 \\
$T_{-1}$ mood & -0.02 & 0.01 & 0.03 \\
$\mathrm{BD}$ & -0.31 & 0.61 & 0.62 \\
$T_{\text {s speed of thoughts }}$ & -0.02 & 0.01 & 0.01 \\
$T_{-1}$ speed of thoughts & - & - & - \\
$\mathrm{BD}$ & -1.78 & 0.90 & 0.07 \\
$T_{\text {Tenergy }}$ & -0.02 & 0.01 & 0.01 \\
$T_{-1}$ energy & -0.01 & 0.01 & 0.04 \\
$\mathrm{BD}$ & -0.25 & 0.66 & 0.70 \\
$T_{\text {impulsivity }}$ & -0.01 & 0.01 & 0.049 \\
$T_{-1}$ impulsivity & - & - & - \\
\hline
\end{tabular}

Model 1 includes the daily core BD evening symptoms during each index day (T); Model 2 includes both the daily core $B D$ evening symptoms during the index day and the day before the index day $\left(\mathrm{T}_{-1}\right)$. Both models are final selected models from two candidate models, which are adjusted for age, gender, employment status, time (days) and the interactions between BD group (not included if not significant). Significant results are in italic lower perceived skill, however, elevated energy was also associated with effort, indicating that greater effort on a task and greater energy were associated in time. Energy was not associated with pain, task preference or social stress. Increased speed of thoughts (Table 3C) was associated with lower perceived skill, but not with pain, task effort, task preference or social stress. Greater impulsivity (Table 3D) was associated with less pain, lower perception of skill, and higher social stress in the BD group, but not associated with task effort or task preference.

\section{Discussion}

In this analysis, we illustrated how extensions of multilevel models could be used to analyze EMA for valid and informative inference, and found significantly elevated within-person variability in core $\mathrm{BD}$ symptoms including mood, energy, speed of thoughts, and impulsivity in the BD group when compared to the $\mathrm{HC}$ group. The EMA method allows for gathering the daily variability of mood and related symptoms in BD [25-27, 33-37]. Traditional methods of assessment ask participants to retrospectively reflect upon mood symptoms over a period of time, and do not always reflect the instability of mood and functioning, which is disruptive to patients. Our study highlights that not only absolute differences in mood states, but also within-subject mood variation over time, can be captured using EMA techniques in patients with BD.

This study results allowed us to look at the effect of self-reported hours of sleep on symptoms the next day. We found that the total hours of sleep reported did not affect symptoms the following day in BD subjects, elevated evening mood, energy and impulsivity were associated with reduced sleep on that night. Our study used a different scale to measure mood, and thus may have captured different facets of this core symptom. Additionally, we measured mood only subjectively and did not have an objective measure that can include physical signs of affect.

We also found that low mood was associated with pain, and elevated mood was associated with more enjoyment of tasks. Increased speed of thoughts and elevated energy were associated with lower perceived skill, which may indicate impairment, though we did not measure impairment directly. Impulsivity was associated with less pain, lower perception of skill and higher social stress in the BD group. Proximal stressful life events have been shown to negatively affect sleep in inter-episode BD [38], and responses to negative events were more stressful for those with BD than $\mathrm{HC}$, which was associated with higher cortisol levels [18, 39]. Detection of changes related to stressors through smartphone technology 
Table 3 The association of pain or social stressors with core BD symptoms at the same timepoint

\begin{tabular}{|c|c|c|c|c|c|c|c|}
\hline A. Mood & Estimate & SE & p-value & B. Energy & Estimate & SE & $p$-value \\
\hline $\mathrm{BD}$ & -15.82 & 7.30 & 0.04 & $\mathrm{BD}$ & -12.72 & 7.27 & 0.09 \\
\hline Pain & -0.12 & 0.05 & 0.01 & Pain & 0.06 & 0.15 & 0.67 \\
\hline $\mathrm{BD}^{*}$ pain & & & & $B D *$ pain & -0.30 & 0.16 & 0.06 \\
\hline $\mathrm{BD}$ & -20.06 & 7.11 & 0.01 & $\mathrm{BD}$ & -23.19 & 6.93 & 0.003 \\
\hline Skill & -0.97 & 0.57 & 0.09 & Skill & -1.48 & 0.66 & 0.03 \\
\hline BD*skill & & & & BD* skill & & & \\
\hline $\mathrm{BD}$ & -20.94 & 7.10 & 0.01 & $B D$ & -25.03 & 6.86 & 0.002 \\
\hline Effort & 0.07 & 0.33 & 0.82 & Effort & 1.29 & 0.37 & 0.001 \\
\hline$B D *$ effort & & & & $B D^{*}$ effort & & & \\
\hline $\mathrm{BD}$ & -30.03 & 7.73 & 0.001 & $\mathrm{BD}$ & -24.63 & 6.97 & 0.002 \\
\hline Preference & -0.51 & 0.53 & 0.34 & Preference & 0.29 & 0.42 & 0.50 \\
\hline $\mathrm{BD}$ * preference & 2.19 & 0.72 & 0.003 & $\mathrm{BD}{ }^{*}$ preference & & & \\
\hline $\mathrm{BD}$ & -20.91 & 7.10 & 0.01 & $\mathrm{BD}$ & -24.39 & 6.97 & 0.002 \\
\hline Social stress & -0.005 & 0.40 & 0.99 & Social stress & -0.10 & 0.47 & 0.82 \\
\hline$B D^{*}$ social stress & & & & $\mathrm{BD}^{*}$ social stress & & & \\
\hline C. Speed of thoughts & Estimate & SE & $p$-value & D. Impulsivity & Estimate & SE & $p$-value \\
\hline $\mathrm{BD}$ & 3.45 & 7.46 & 0.65 & $\mathrm{BD}$ & 16.62 & 7.97 & 0.048 \\
\hline Pain & -0.10 & 0.06 & 0.10 & Pain & 0.68 & 0.19 & $<0.001$ \\
\hline $\mathrm{BD}^{*}$ pain & & & & $B D *$ pain & -0.72 & 0.20 & $<0.001$ \\
\hline $\mathrm{BD}$ & 0.62 & 6.69 & 0.93 & $\mathrm{BD}$ & 21.11 & 7.97 & 0.01 \\
\hline Skill & -1.49 & 0.71 & 0.04 & Skill & 2.68 & 1.46 & 0.07 \\
\hline$B D *$ skill & & & & $B D *$ skill & -4.66 & 1.77 & 0.01 \\
\hline $\mathrm{BD}$ & -1.01 & 6.51 & 0.88 & $\mathrm{BD}$ & 11.27 & 7.37 & 0.14 \\
\hline Effort & 0.77 & 0.41 & 0.06 & Effort & -0.29 & 0.48 & 0.55 \\
\hline$B D *$ effort & & & & $B D^{*}$ effort & & & \\
\hline $\mathrm{BD}$ & -0.74 & 6.60 & 0.91 & $\mathrm{BD}$ & 11.42 & 7.36 & 0.14 \\
\hline Preference & 0.08 & 0.46 & 0.85 & Preference & -0.40 & 0.54 & 0.46 \\
\hline $\mathrm{BD}{ }^{*}$ preference & & & & $\mathrm{BD}{ }^{*}$ preference & & & \\
\hline $\mathrm{BD}$ & -0.84 & 6.60 & 0.90 & $\mathrm{BD}$ & 1.62 & 8.12 & 0.84 \\
\hline Social stress & 0.27 & 0.50 & 0.59 & Social stress & -2.20 & 0.86 & 0.01 \\
\hline $\mathrm{BD}^{*}$ social stress & & & & BD* social stress & 3.18 & 1.17 & 0.007 \\
\hline
\end{tabular}

A. mood, B. energy, C. speed of thoughts, D. impulsivity. Thoughts: speed of thoughts; Skill: perception of skill; Preference: preference of tasks. All models are adjusted for age, adjusted for age, gender, employment status, time (days). Significant results are in italic

between office visits or encounters with the health care team may allow for the opportunity to intervene and prevent mood episodes.

Through the use of EMA, we detected daily variability in BD symptoms and associations between daily mood, energy, and impulsivity symptoms in BD, sleep and daily stressors. Further exploration of the proximal relationship between daily stressors, sleep and mood is needed.

\section{Limitations}

There are some limitations to this study. This study was designed to demonstrate feasibility; therefore, the sample size was small. In future studies, we will extend our study period in a larger sample, which is ongoing now.
This report does not address the psychometric properties of the items. Also, certain biases and confounding factors are still present when using smart phones to capture data, which needs more exploration.

\section{Supplementary information}

Supplementary information accompanies this paper at https://doi. org/10.1186/s13104-019-4834-7.

Additional file 1. More detailed information on study enrollment, data structure and statistical analysis.

Abbreviations

EMA: Ecological Momentary Assessment; BD: bipolar disorder; HC: healthy control; IRB: Institutional review board; MINI 5.0: Mini-International 
Neuropsychiatric Interview, version 5.0; DREAM: Dynamic Real-Time Ecological Ambulatory Methodologies.

\section{Acknowledgements}

The authors acknowledge the patients and families that made this study possible. In addition, we acknowledge the Penn State Clinical \& Translational Research Institute and Pennsylvania State University for providing funding this project.

\section{Authors' contributions}

$\mathrm{HL}$ analyzed the data and wrote the first draft of the paper. DM, VK, CM, and KR made substantial contributions to the analysis and interpretation of the data; LZ made substantial contributions to methods review, the analysis the data and table generations in particular for paper revision; ES made substantial contributions to the conception and design, acquisition of data and analysis and interpretation of data; MW made substantial contributions to the conception and design, analysis and interpretation of data. All authors were involved in revising the manuscript critically, all gave final approval of the version to be published, and all agree to be accountable for all aspects of the work. All authors read and approved the final manuscript.

\section{Funding}

This publication (or project) was supported by the Penn State Clinical \& Translational Research Institute, Pennsylvania State University CTSA, NIH/NCATS Grant Number UL1 TR000127 and UL1 TR002014. The contents are solely the responsibility of the authors and do not necessarily represent the official views of the NIH or NCATS. The funding agencies were not involved with the design of the study and collection, analysis, and interpretation of data and in writing the manuscript.

\section{Availability of data and materials}

The datasets supporting the conclusions of this article is available based upon reasonable request.

\section{Ethics approval and consent to participate}

The research was approved by the institutional review board (IRB) at the Hershey Medical Center (PSU COM IRB \# 00251, approval 3/28/2014), and written consent was obtained from each participant.

\section{Consent to publish}

Not applicable.

\section{Competing interests}

$\mathrm{HL}, \mathrm{DM}, \mathrm{VK}$ reports no conflicts. CM receives salary support through the Sackler Scholars in Psychobiology Program. KR has received grant funding through National Center for Advancing Translational Sciences of the National Institutes of Health under Award Number 2KL2TR000434, the Heinz C. Prechter Research Program, and the Richard Tam Foundation. LZ has received grant funding from the Pennsylvania State University, Penn State Clinical and Translational Science Institute and the National Institutes of Health. ES receives a stipend from the Journal of Clinical Psychiatry for an associate editorship, and has received grant funding from the National Institutes of Health and the Stanley Medical Research Institute. MW has received grant funding from the Pennsylvania State University, Pennsylvania Department of Health, Penn State Clinical and Translational Science Institute, Grant No. KL2 TR 126-4, the National Institutes of Health, BioAdvance, and the Children's Miracle Network at Penn State.

\footnotetext{
Author details

${ }^{1}$ Department of Public Health Science, Penn State College of Medicine, Penn State Milton S. Hershey Medical Center, 90 Hope Drive, Hershey, PA 17033, USA. ${ }^{2}$ Department of Psychiatry, Penn State College of Medicine, Penn State Milton S. Hershey Medical Center, Hershey, PA, USA. ${ }^{3}$ Department of Psychiatry, University of Michigan Medical School, Ann Arbor, MI, USA. ${ }^{4}$ Institute of Personalized Medicine, Penn State College of Medicine, Penn State Milton S. Hershey Medical Center, Hershey, PA, USA.

Received: 24 November 2019 Accepted: 28 November 2019

Published online: 04 December 2019
}

\section{References}

1. APA. Diagnostic and statistical manual of mental disorders: DSM-5. 5th ed. Washington, D.C.: American Psychiatric Association; 2013.

2. Merikangas KR, Akiskal HS, Angst J, Greenberg PE, Hirschfeld RM, Petukhova M, Kessler RC. Lifetime and 12-month prevalence of bipolar spectrum disorder in the National Comorbidity Survey replication. Arch Gen Psychiatry. 2007;64(5):543-52.

3. Harding KJ, Rush AJ, Arbuckle M, Trivedi MH, Pincus HA. Measurementbased care in psychiatric practice: a policy framework for implementation. J Clin Psychiatry. 2011;72(8):1136-43.

4. Ghaemi SN. Feeling and time: the phenomenology of mood disorders, depressive realism, and existential psychotherapy. Schizophr Bull. 2007;33(1):122-30.

5. Judd LL, Akiskal HS, Schettler PJ, Endicott J, Maser J, Solomon DA, Leon AC, Rice JA, Keller MB. The long-term natural history of the weekly symptomatic status of bipolar I disorder. Arch Gen Psychiatry. 2002;59(6):530-7.

6. Bauer M, Glenn T, Grof P, Schmid R, Pfennig A, Whybrow PC. Subsyndromal mood symptoms: a useful concept for maintenance studies of bipolar disorder? Psychopathology. 2010;43(1):1-7.

7. Judd LL, Akiskal HS, Schettler PJ, Endicott J, Leon AC, Solomon DA, Coryell W, Maser JD, Keller MB. Psychosocial disability in the course of bipolar I and II disorders: a prospective, comparative, longitudinal study. Arch Gen Psychiatry. 2005;62(12):1322-30.

8. Perlis RH, Ostacher MJ, Patel JK, Marangell LB, Zhang H, Wisniewski SR, Ketter TA, Miklowitz DJ, Otto MW, Gyulai L, et al. Predictors of recurrence in bipolar disorder: primary outcomes from the Systematic Treatment Enhancement Program for Bipolar Disorder (STEP-BD). Am J Psychiatry. 2006;163(2):217-24.

9. Bilderbeck AC, Reed ZE, McMahon HC, Atkinson LZ, Price J, Geddes JR, Goodwin GM, Harmer CJ. Associations between mood instability and emotional processing in a large cohort of bipolar patients. Psychol Med. 2016;46(15):3151-60.

10. Simon GE, Bauer MS, Ludman EJ, Operskalski BH, Unutzer J. Mood symptoms, functional impairment, and disability in people with bipolar disorder: specific effects of mania and depression. J Clin Psychiatry. 2007;68(8): 1237-45

11. Proudfoot J, Whitton AE, Parker G, Manicavasagar V, Nicholas J, Smith M. Evidence of weekly cyclicity in mood and functional impairment in those with a bipolar disorder. Psychiatry Res. 2014;218(3):290-4.

12. Saunders EF, Fernandez-Mendoza J, Kamali M, Assari S, McInnis MG. The effect of poor sleep quality on mood outcome differs between men and women: a longitudinal study of bipolar disorder. J Affect Disord. 2015;180:90-6.

13. Saunders EF, Novick DM, Fernandez-Mendoza J, Kamali M, Ryan KA, Langenecker SA, Gelenberg AJ, McInnis MG. Sleep quality during euthymia in bipolar disorder: the role of clinical features, personality traits, and stressful life events. Int J Bipolar Disord. 2013;1(16):16.

14. Gershon A, Thompson WK, Eidelman P, McGlinchey EL, Kaplan KA, Harvey AG. Restless pillow, ruffled mind: sleep and affect coupling in interepisode bipolar disorder. J Abnorm Psychol. 2012;121(4):863-73.

15. Gruber J, Miklowitz DJ, Harvey AG, Frank E, Kupfer D, Thase ME, Sachs GS, Ketter TA. Sleep matters: sleep functioning and course of illness in bipolar disorder. J Affect Disord. 2011;134(1-3):416-20.

16. Myin-Germeys I, Oorschot M, Collip D, Lataster J, Delespaul P, van Os J. Experience sampling research in psychopathology: opening the black box of daily life. Psychol Med. 2009;39(9):1533-47.

17. Myin-Germeys I, Peeters F, Havermans R, Nicolson NA, DeVries MW, Delespaul P, Van Os J. Emotional reactivity to daily life stress in psychosis and affective disorder: an experience sampling study. Acta Psychiatr Scand. 2003;107(2):124-31.

18. Havermans R, Nicolson NA, Berkhof J, deVries MW. Patterns of salivary cortisol secretion and responses to daily events in patients with remitted bipolar disorder. Psychoneuroendocrinology. 2011;36(2):258-65.

19. aan het Rot M, Hogenelst K, Schoevers RA. Mood disorders in everyday life: a systematic review of experience sampling and ecological momentary assessment studies. Clin Psychol Rev. 2012;32(6):510-23.

20. Shiffman S, Stone AA, Hufford MR. Ecological momentary assessment. Annu Rev Clin Psychol. 2008;4:1-32.

21. Moskowitz DS, Young SN. Ecological momentary assessment: what it is and why it is a method of the future in clinical psychopharmacology. J Psychiatry Neurosci. 2006;31(1):13-20. 
22. Bauer M, Grof P, Gyulai L, Rasgon N, Glenn T, Whybrow PC. Using technology to improve longitudinal studies: self-reporting with ChronoRecord in bipolar disorder. Bipolar Disord. 2004;6(1):67-74.

23. Bauer M, Rasgon N, Grof P, Gyulai L, Glenn T, Whybrow PC. Does the use of an automated tool for self-reporting mood by patients with bipolar disorder bias the collected data? MedGenMed. 2005;7(3):21.

24. Miklowitz DJ, Price J, Holmes EA, Rendell J, Bell S, Budge K, Christensen J, Wallace J, Simon J, Armstrong NM, et al. Facilitated Integrated Mood Management for adults with bipolar disorder. Bipolar Disord. 2012;14(2):185-97.

25. Faurholt-Jepsen $M$, Vinberg $M$, Christensen EM, Frost M, Bardram J, Kessing LV. Daily electronic self-monitoring of subjective and objective symptoms in bipolar disorder - the MONARCA trial protocol (MONitoring, treAtment and pRediCtion of bipolAr disorder episodes): a randomised controlled single-blind trial. BMJ Open. 2013. https://doi.org/10.1136/ bmjopen-2013-003353.

26. Depp CA, Ceglowski J, Wang VC, Yaghouti F, Mausbach BT, Thompson WK, Granholm EL. Augmenting psychoeducation with a mobile intervention for bipolar disorder: a randomized controlled trial. J Affect Disord. 2015;174:23-30.

27. Depp CA, Kim DH, de Dios LV, Wang V, Ceglowski J. A pilot study of mood ratings captured by mobile phone versus paper-and-pencil mood charts in bipolar disorder. J Dual Diagn. 2012;8(4):326-32.

28. Schwartz S, Schultz S, Reider A, Saunders EF. Daily mood monitoring of symptoms using smartphones in bipolar disorder: a pilot study assessing the feasibility of ecological momentary assessment. J Affect Disord. 2016:191:88-93.

29. Sheehan DV, Lecrubier $Y$, Sheehan $\mathrm{KH}$, Amorim P, Janavs J, Weiller E, Hergueta T, Baker R, Dunbar GC. The Mini-International Neuropsychiatric Interview (M.I.N.I.): the development and validation of a structured diagnostic psychiatric interview for DSM-IV and ICD-10. J Clin Psychiatry. 1998;59(Suppl 20):22-33 (quiz 34-57).

30. Snijders TAB, Bosker RJ. Multilevel analysis: an introduction to basic and advanced multilevel modeling. 2nd ed. Los Angeles: Sage; 2012.

31. Raudenbush SW, Bryk AS. Hierarchical linear models: applications and data analysis methods. 2nd ed. Thousand Oaks: Sage Publications; 2002.
32. Hoffman L. Multilevel models for examining individual differences in within-person variation and covariation over time. Multivar Behav Res. 2007:42(4):609-29.

33. Faurholt-Jepsen M, Brage S, Vinberg M, Jensen HM, Christensen EM, Knorr $U$, Kessing LV. Electronic monitoring of psychomotor activity as a supplementary objective measure of depression severity. Nord J Psychiatry. 2015;69(2):118-25.

34. Faurholt-Jepsen M, Vinberg M, Frost M, Christensen E, Bardram J, Kessing L. Daily electronic monitoring of subjective and objective measures of illness activity in bipolar disorder using smartphones inverted question mark the MONARCA II trial protocol: a randomized controlled singleblind parallel-group trial. BMC Psychiatry. 2014;14(1):309.

35. Faurholt-Jepsen M, Frost M, Vinberg M, Christensen EM, Bardram JE, Kessing LV. Smartphone data as objective measures of bipolar disorder symptoms. Psychiatry Res. 2014;217(1-2):124-7.

36. Thompson WK, Gershon A, O'Hara R, Bernert RA, Depp CA. The prediction of study-emergent suicidal ideation in bipolar disorder: a pilot study using ecological momentary assessment data. Bipolar Disord. 2014;16(7):669-77.

37. Depp CA, Mausbach B, Granholm E, Cardenas V, Ben-Zeev D, Patterson $T L$, Lebowitz BD, Jeste DV. Mobile interventions for severe mental illness: design and preliminary data from three approaches. J Nerv Ment Dis. 2010;198(10):715-21.

38. Saunders EF, Novick DM, Fernandez-Mendoza J, Kamali M, Ryan KA, Langenecker SA, Gelenberg AJ, McInnis MG. Sleep quality during euthymia in bipolar disorder: the role of clinical features, personality traits, and stressful life events. Int J Bipolar Disord. 2013:1:16.

39. Havermans R, Nicolson NA, Berkhof J, deVries MW. Mood reactivity to daily events in patients with remitted bipolar disorder. Psychiatry Res. 2010;179(1):47-52.

\section{Publisher's Note}

Springer Nature remains neutral with regard to jurisdictional claims in published maps and institutional affiliations.
Ready to submit your research? Choose BMC and benefit from:

- fast, convenient online submission

- thorough peer review by experienced researchers in your field

- rapid publication on acceptance

- support for research data, including large and complex data types

- gold Open Access which fosters wider collaboration and increased citations

- maximum visibility for your research: over $100 \mathrm{M}$ website views per year

At $\mathrm{BMC}$, research is always in progress.

Learn more biomedcentral.com/submissions 